\title{
Essential Type II Mixed Cryoglobulinemia Causing Pyoderma Gangrenosum-Like Ulcers
}

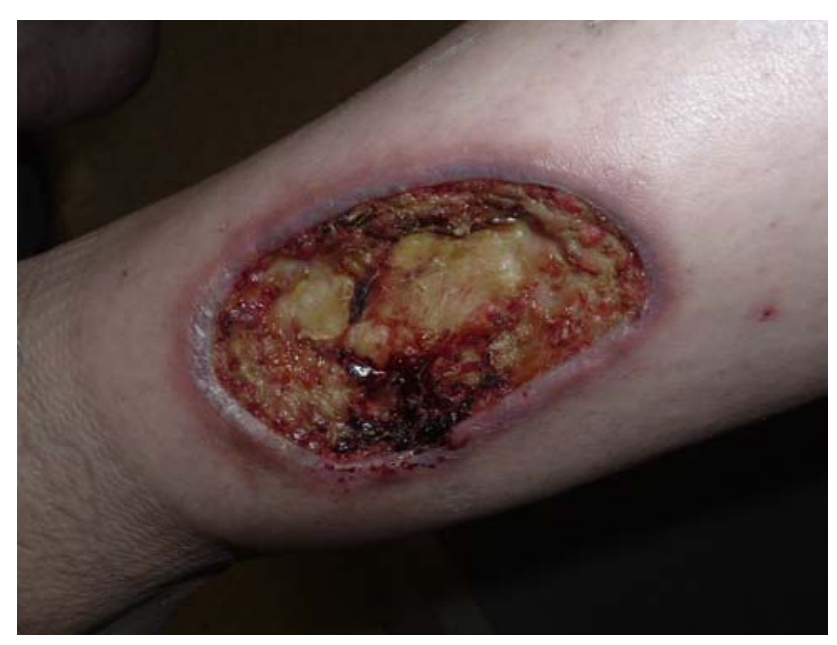

Figure. Pyoderma gangrenosum-like lesions due to cryoglobulinemia.

\author{
M.R. Namazi ${ }^{1,2, \star}$, K.R. Kerchner ${ }^{1}$, and R.O. Pichardo ${ }^{1}$ \\ ${ }^{1}$ Dermatology Department, Wake-Forest University Baptist Medical Center, North \\ Carolina; ${ }^{2}$ Dermatology Department, Shiraz University of Medical Sciences, Shiraz, \\ Iran \\ E-mail: namazi mr@yahoo.com
}

Received January 29, 2008; Revised January 29, 2008; Accepted February 4, 2008; Published February 25, 2008

A 47-year-old, otherwise healthy woman presented with multiple deep ulcers located primarily on her lower extremities that presented 6 days ago as blisters. A biopsy revealed livedoid vasculopathy, without any evidence of vasculitis. Extensive laboratory workup was positive only for type II cryoglobulins.

Type II cryoglobulinemia is caused by monoclonal rheumatoid factors. Cutaneous manifestations are nearly always present in cryoglobulinemia. Lesions have a predilection for dependent areas and include erythematous macules and purpuric papules (90-95\%), as well as ulcerations (10-25\%). Livedo reticularis, Raynaud phenomenon, and nailfold capillary abnormalities are also noted. Presentation with deep ulcers may lead to a misdiagnosis of pyoderma gangrenosum.

This article should be cited as follows:

Namazi, M.R., Kerchner, K.R., and Pichardo, R.O. (2008) Essential type II mixed cryoglobulinemia causing pyoderma gangrenosum-like ulcers. TheScientificWorldJOURNAL 8, 228. DOI 10.1100/tsw.2008.44. 


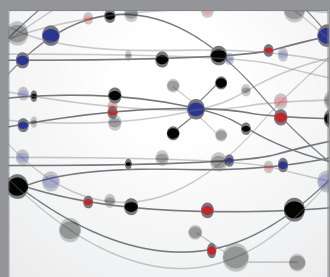

The Scientific World Journal
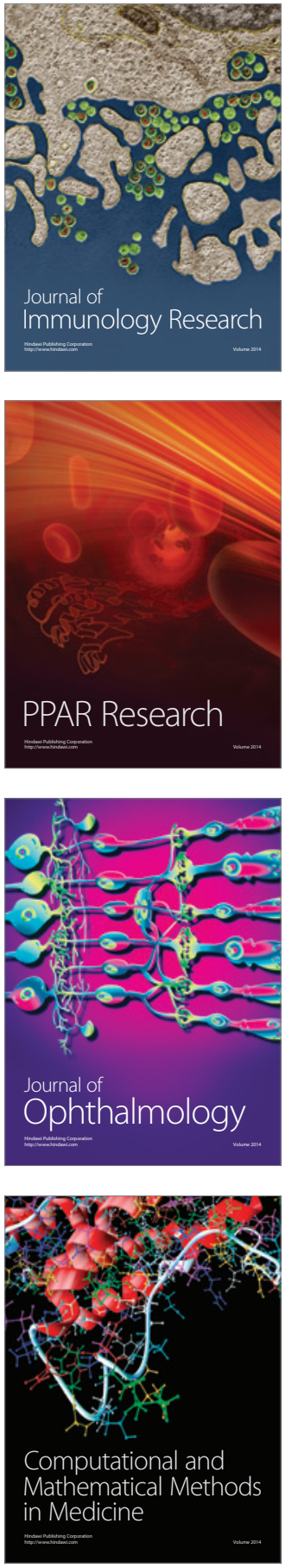

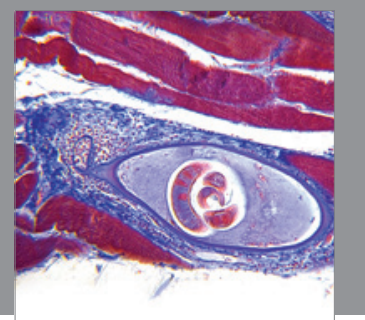

Gastroenterology

Research and Practice
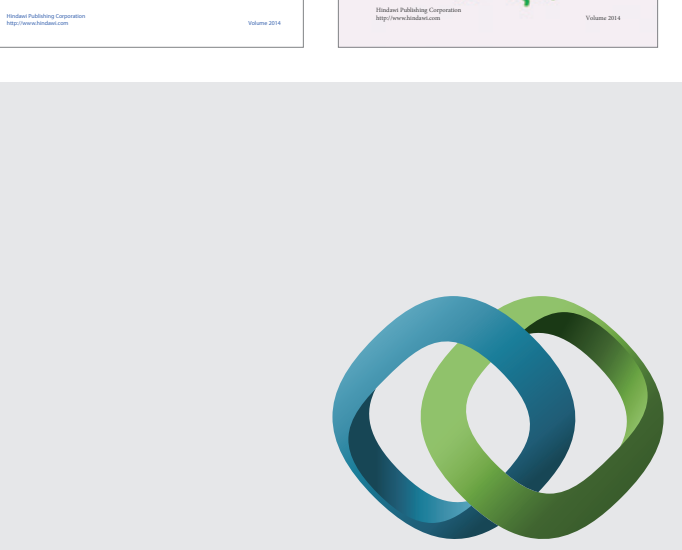

\section{Hindawi}

Submit your manuscripts at

http://www.hindawi.com
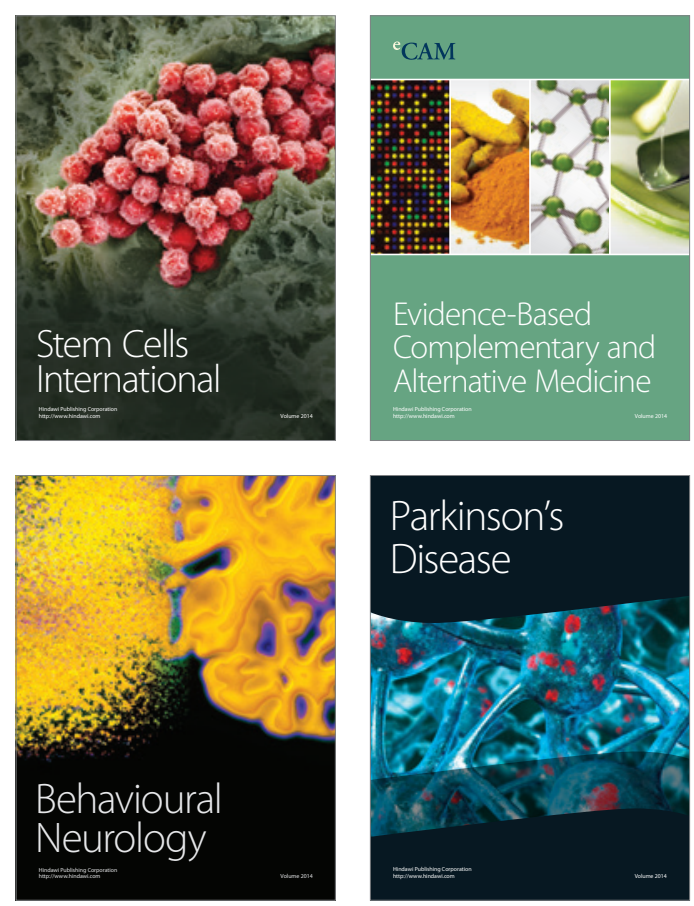

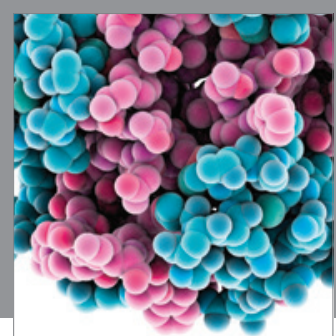

Journal of
Diabetes Research

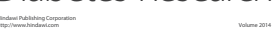

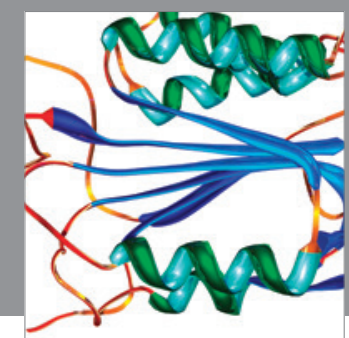

Disease Markers
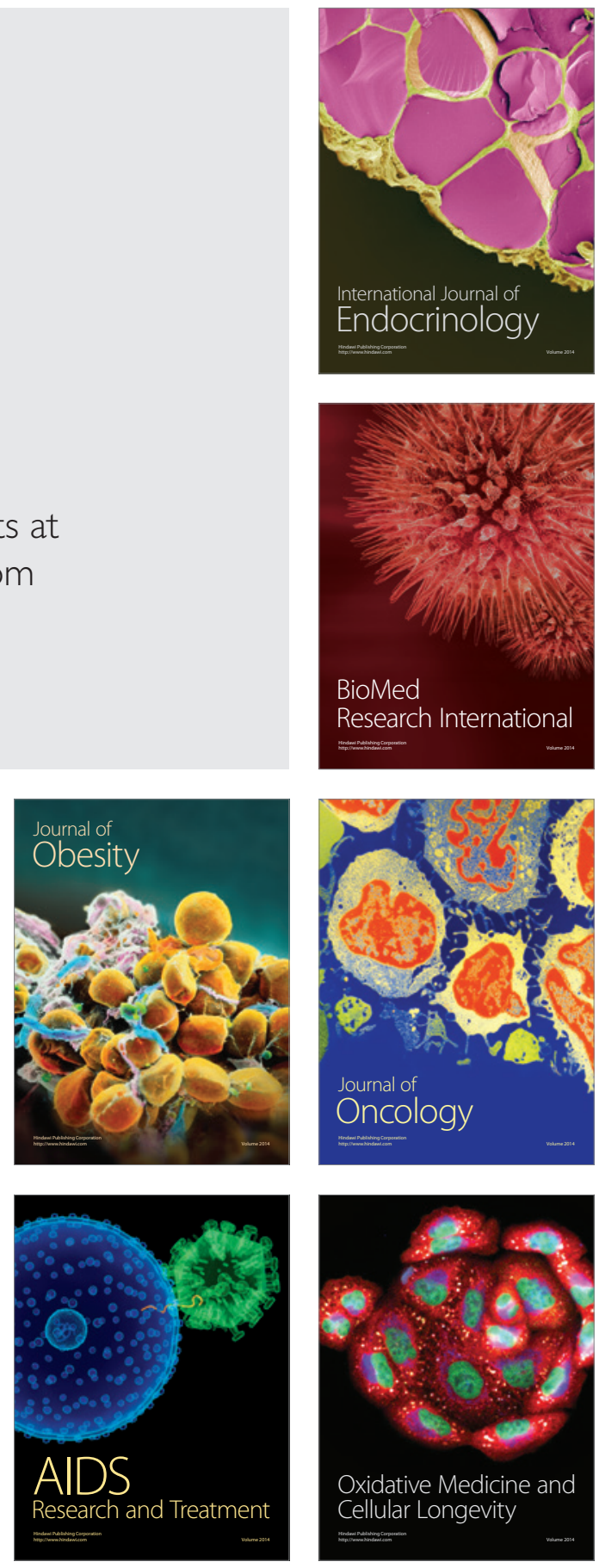